\title{
Diário escrito para a posteridade: os diários de Getúlio Vargas
}

DOI: http://dx.doi.org/10.21165/el.v48i2.2274

\section{Nathalia Reis Fernandes ${ }^{1}$}

\section{Resumo}

Ainda que tenha inicialmente mantido seu material em segredo, o autor de um diário pode deixar marcas sutis de seu intuito, que permitem descortinar um desejo velado de exposição. Isso pode se manifestar na atenção ao suporte material em que escreve, no traçado dos caracteres ou outros elementos de fundo codicológico que compõem o material. Nesse sentido, com base em tese de doutorado que abordou, entre outras questões, a caracterização do gênero discursivo "diário", e com inspiração no documentário Imagens do Estado Novo 1937-45, de Eduardo Escorel (2016), procuraremos analisar se tais características estariam presentes no diário de Getúlio Vargas, escrito entre 1930 e 1942, material em que se pode notar uma variação nos elementos codicológicos ao longo do tempo. Compararemos essas escolhas do autor com os padrões de outros diários, a fim de sustentar nossas conclusões.

Palavras-chave: diário, gênero discursivo, codicologia, edição de manuscritos.

1 Universidade de São Paulo (USP), São Paulo, São Paulo, Brasil; nathlet@gmail.com; https://orcid.org/0000-0002-1862-7835 


\title{
A diary for posterity: Getúlio Vargas' diaries
}

\begin{abstract}
The author of a diary may leave marks of some desire of exposition, even when keeping his/her material secret. These marks can be seen on care for the material support in which he/she writes, calligraphy or other codicological elements. Based on a PhD thesis, which aimed to characterize the discursive genre called "diary", and inspired by Eduardo Escorel's movie Imagens do Estado Novo 1937-45 (2016), we will check if these marks are present at Getúlio Vargas' diaries, written between 1930 and 1942, in which there is a visible change in codicological elements through time. We will compare these choices with patterns seen in other diaries.
\end{abstract}

Keywords: diary, discursive genre, codicology, manuscript edition.

\section{Introdução}

A produção do material escrito envolve uma série de eventos e apresenta outros indicativos e características, tão afeitos à análise do discurso, à filologia e à crítica genética. Análises desse tipo são instigantes e dão pistas sobre a riqueza literária e psicológica do autor e suas criações.

Os diários, que têm sido tema de nosso estudo desde o doutorado, permitem análises bastante particularizadas a esse respeito. E, ao descobrirmos os diários de Getúlio Vargas, por meio do documentário Imagens do Estado Novo 1937-45, de Eduardo Escorel (2016), que esteve em cartaz no início de 2018, em primeiro momento nos chamou a atenção a caligrafia cuidadosa e o bom aproveitamento da mancha. Tudo muito "apresentável", como convém a um chefe de Estado. Logo imaginamos o quanto disso teria sido calculado estrategicamente, como se a intenção do escriba fosse transmitir uma imagem específica de si quando o material viesse a público.

Neste caso em especial, inicialmente isso não soa estranho - afinal, estamos tratando de uma personagem histórica que, quando de seu suicídio, pode ter deixado uma mensagem muito específica a respeito do que motivava aquele ato, talvez contida na famosa frase "Saio da vida para entrar na História": a preservação da autoimagem.

A consulta aos volumes que compõem o diário, por meio do website do Centro de Documentação da Fundação Getúlio Vargas (CPDOC-FGV-RJ), nos mostrou um cenário um pouco mais diversificado, com os diários iniciais, da época em que Getúlio foi instalado no poder pela Junta Provisória que destituiu Washington Luiz, mais impulsivos (considerando, nesse sentido, apenas os aspectos codicológicos) e escritos sobre suporte que passa a impressão de improviso. 
O aumento do cuidado com o suporte físico e com a disposição do texto aumenta conforme o tempo passa - e o autor começa a se firmar no poder.

Imediatamente, passamos a considerar o quanto esse material não teria progredido, codicologicamente, em paralelo com seu autor, conectado a essa imagem que ele pretendia construir. E, em continuidade aos estudos desenvolvidos em nossa tese, iniciamos uma nova pesquisa, abrangendo a edição do material e análise que visa confirmar aquela possibilidade.

Apresentamos, aqui, um recorte da pesquisa restrito à exposição de sua linha condutora, com as percepções e resultados obtidos até o momento.

\section{0 gênero diário. Classificação dos diários em estudo}

Antes de mais nada, vale a pena ressaltar que muitos textos de fundo memorialista são genericamente denominados "diários", sem que necessariamente se apresente o gênero discursivo diário. ${ }^{2}$

Em tese de doutorado (FERNANDES, 2017), desenvolveu-se, com base no ideário bakhtiniano sobre os gêneros do discurso, um rol de características que permite afirmar que determinada produção escrita, com foco na preservação da memória, assume o gênero discursivo diário:

a) os fatos convergem para a pessoa do autor;

b) a visão do escriba sobre tais fatos é unilateral;

c) os fatos fazem parte da rotina do autor e estão ligados ao projeto discursivo, o elemento subjetivo presente no discurso;

d) há indicação da data dos fatos e da sequência cronológica em que se desenvolvem.

No material ora em estudo, não há dúvida de que estamos diante do gênero discursivo diário. As características acima descritas se encaixam nele com clareza:

a) os fatos descritos têm por foco a pessoa de Getúlio Vargas e sua atuação política. A exceção fica por conta de um trecho que se encontra no primeiro caderno, que parece um

2 A partir deste ponto, o termo "diário", entre aspas, será usado para esse sentido mais coloquial da palavra; sem aspas, pressupõe-se que a referência é feita ao gênero discursivo diário. 
rascunho de análise a respeito de um contrato. Porém, essa análise tem relação direta com a atividade do autor;

b) a visão de Getúlio sobre os fatos é unilateral, com trechos de análises sobre o comportamento de determinados atores políticos e situações;

c) os fatos descritos estão diretamente relacionados à rotina de Getúlio como presidente e figura política, o que pode indicar um projeto discursivo ligado ao desempenho dessas funções. Há poucas referências à vida estritamente pessoal, fora do papel público que desempenhava, mas a rotina "principal", ligada ao projeto discursivo, está presente nos cadernos;

d) os fatos estão datados e claramente dispostos em sequência cronológica; em alguns casos, o autor opta por descrever fatos ligados a um bloco de dias.

Não há dúvida, portanto, de que estamos diante de um diário.

\section{Filologia como suporte discursivo}

Antes de passarmos à análise dos diários, faz-se necessário expor a relação interessante que a filologia e a análise do discurso podem estabelecer.

A filologia, no estado atual da arte, tem sido definida como a ciência que designa o estudo global de um texto, a exploração exaustiva e conjunta dos mais variados aspectos de um texto - linguístico, literário, crítico-textual, sócio-histórico (CAMBRAIA, 2005). Nesse contexto, a codicologia, o estudo da técnica do livro manuscrito, funciona como saber adjunto, que permite a compreensão do processo de elaboração e transmissão dos textos (CAMBRAIA, 2005), a partir da análise de questões materiais como as dimensões do livro, tipos de suporte material, particularidades do suporte e encadernação.

Não obstante, a filologia e, mais especificamente, a codicologia são, no mais das vezes, vistas como apoio ao estudo fonético, morfológico etc., num papel mais coadjuvante do que de protagonismo - uma vez que o suporte não se apresenta da forma a que estamos acostumados nos dias de hoje, ou contém determinadas particularidades que demandam estudo, o estudioso se socorre dos elementos filológicos e codicológicos para "decifrar" o material à sua frente.

Porém, essas duas áreas do conhecimento podem ser de fundamental força para a análise do discurso, uma vez que esta, para melhor compreender o texto, pode (e precisa) se utilizar de questões históricas e sociais. 
Já existem trabalhos buscando a aproximação entre filologia e discurso (v. p. ex., MUNHOZ, 2015), mas, em nosso caso, pretendemos analisar os significados contidos no ponto mais físico, mais concreto do texto, exposto no suporte material, na grafia etc. e deixá-los expostos - os quais, por sua vez, também são indicadores de como o mesmo discurso está organizado, para além das palavras e de seu encadeamento em texto.

\subsection{Codicologia e enunciado}

Para fazer essa ponte, vamos nos utilizar da teoria bakhtiniana, mais precisamente do conceito de enunciado: a unidade real da comunicação discursiva, caracterizada pela alternância de sujeitos falantes, conclusibilidade e escolha de um gênero discursivo (cf. GRUPO DE ESTUDOS DOS GÊNEROS DO DISCURSO, 2009, resumindo o quanto consta em BAKHTIN, 2008).

O enunciado pressupõe três fatores: o horizonte espacial comum dos interlocutores, isto é, aquilo que é visível; o conhecimento e a compreensão comum da situação pelos mesmos interlocutores; e sua avaliação comum da situação (BRAIT; MELO, 2008).

Desses dados se depreende que o enunciado exige, necessariamente, interatividade entre um autor e um destinatário; este último não precisa estar concretizado e pode mesmo ser um sobredestinatário, sem limitação de fronteiras de espaço e tempo (BRAIT; MELO, 2008). Além disso, sendo necessária para a sua composição aquilo que é visível e está ao alcance dos interlocutores, tudo o que está associado ao enunciado acaba por se tornar relevante.

Até porque, segundo Bakhtin (2017, p. 49), o ato não pode ser avaliado sem que haja consideração simultânea do pensamento abstrato e o que existe de concreto e disponível:

\footnotetext{
E, assim, enquanto separamos um juízo da unidade da ação-ato historicamente real de sua atuação e o relacionamos a uma unidade teórica qualquer, do interior de seu conteúdo-sentido, não há saída que conduza ao dever no evento real singular do existir. Qualquer que seja a tentativa de superar o dualismo entre consciência e vida, entre o pensamento e a realidade concreta singular é, do interior do conhecimento teórico, absolutamente sem esperança .
}

Tomando essas ideias para fortalecermos a vinculação entre codicologia e discurso, podemos, portanto, afirmar que os elementos codicológicos, sendo parte integrante do suporte material em que se insere determinada produção textual, fazem parte da "ambiência", do horizonte espacial que é compartilhado pelo autor e pelo leitor, e, portanto, também fazem parte do enunciado. 
Eles estão repletos de símbolos, de significância, que podem permitir uma visão muito mais ampla do enunciado; 3 tais símbolos permitem que não só o filólogo e o analista do discurso, mas também o leitor leigo, possam situar o enunciado representado pela obra dentro de um contexto muito mais amplo do que aquele indicado apenas pela produção verbal ali contida.

\title{
3.2 Gênero diário e exposição pessoal
}

Os elementos codicológicos, somados à escolha do gênero do discurso, podem trazer à tona mais informações sobre o enunciado.

Um gênero do discurso é um "tipo relativamente estável de enunciado", o qual serve a um campo da utilização da língua (BAKHTIN, 2003, p. 262); não é uma espécie ou modalidade de composição, mas um dispositivo de organização, troca, divulgação, armazenamento, transmissão e, sobretudo, criação de mensagens (MACHADO, 2008), estabelecendo uma interconexão da linguagem com a vida social (FIORIN, 2008). A diversidade dos gêneros é determinada por situação, posição social e relações pessoais de reciprocidade entre os participantes da comunicação (BAKHTIN, 2003).

A escolha de um desses dispositivos também diz sobre as intenções do falante:

\begin{abstract}
A vontade discursiva do falante se realiza antes de tudo na escolha de um certo gênero do discurso. Essa escolha é determinada pela especificidade de um dado campo da comunicação discursiva, por considerações semântico-objetais (temáticas), pela situação concreta da comunicação discursiva, pela composição pessoal dos seus participantes, etc. A intenção discursiva do falante, em toda a sua individualidade e subjetividade, é em seguida aplicada e adaptada ao gênero escolhido, constitui-se e desenvolve-se em uma determinada forma de gênero. (BAKHTIN, 2003, p. 282).
\end{abstract}

Ora, quando da exposição da caracterização do gênero diário, vimos que este se volta a questões cotidianas, ligadas à pessoa do autor e expressando visão unilateral dos fatos. É fácil concluir que, neste gênero, há um alto nível de pessoalidade. É um tipo de registro que dá conta de dados que, possivelmente, apenas o autor tenha conhecimento, ou de

3 "O enunciado é da ordem do sentido; o texto, do domínio da manifestação. O enunciado não é manifestado apenas verbalmente, o que significa que, para Bakhtin, o texto não é exclusivamente verbal, pois é qualquer conjunto coerente de signos, seja qual for sua forma de expressão (pictórica, gestual etc.)" (FIORIN, 2008, p. 52). 
opiniões que ele não tem a intenção de expressar fora daquele âmbito. Há um desejo de exposição, que tende a permanecer velado, restrito ao conhecimento do autor, a menos que haja posterior publicação do material. ${ }^{4}$

Note-se que a não divulgação de um diário por ato deliberado do seu autor não significa que não haja interação autor-destinatário que sustente o enunciado. A relação pode se estabelecer com um destinatário incerto, como inclusive já expusemos em outro item. No caso do diário, pode-se imaginar como possibilidades a posteridade, a história, ainda mais em se tratando de personalidades públicas.

Optar pelo gênero discursivo diário é, pois, expor a si mesmo de forma bastante intimista, a partir do momento em que opiniões e fatos descritos por uma visão unilateral são registrados. E, se considerarmos o caso singular de Getúlio Vargas, é possível que estejamos diante de um projeto de imagem que ele, enquanto pessoa pública, pretendia deixar, e que, como mencionado anteriormente, pode ter sido imortalizado na famosa carta em que justificava seu suicídio, bem como em outras situações de indução ao culto de sua personalidade pelo seu departamento de propaganda, na época do Estado Novo (o "pai dos pobres", referência das medidas trabalhistas etc.) (cf., a respeito, VARGAS, 2001, verbete em versão HTML do Dicionário histórico-biográfico brasileiro, de onde foram retiradas as referências históricas para a composição deste artigo, salvo indicação em contrário).

\section{Avaliação da "evolução" codicológica dos "diários"}

Feitas essas considerações, passamos a avaliar os aspectos codicológicos do material em questão.

Até o momento, não tivemos oportunidade de consultar a versão original dos treze cadernos que abrigam os "diários", arquivados no Rio de Janeiro, e a descrição física do material não consta do site do CPDOC, que os disponibiliza em formato digital. Portanto, algumas questões codicológicas muito específicas, como as dimensões dos cadernos, gramatura e tipo de papel, ainda não podem ser esclarecidas. Nossa argumentação toma por base o formato e a quantidade das páginas, o espaço ocupado pela mancha (a parte da página preenchida pelo texto) e o material usado para a escrita (lápis e caneta), além de outras particularidades físicas que porventura se apresentem.

4 Já existe uma transcrição do manuscrito, publicada pela FGV/Siciliano em 1995. Em nosso estudo, levaremos a efeito uma edição nossa, até para que haja maior envolvimento com o material e verificação de eventuais outras questões codicológicas que possam ser interessantes para nossos objetivos. 
A análise que já fizemos do material em questão apurou que ocorre uma interessante "evolução" dos aspectos codicológicos ao longo da carreira política de Getúlio - como se ele reproduzisse seu crescimento pessoal no cuidado que tem com o aspecto material envolvido no texto.

Em vista do espaço disponível, e considerando o fato de que nosso estudo a respeito ainda está em andamento, é impossível fazer uma análise pormenorizada de todo o material, o que nos obriga a selecionar trechos em que as variações codicológicas são mais visíveis.

\subsection{Volume $1929(?)-10.10 .1930$}

Este volume é composto por um caderno que parece ser pequeno, tem pouco espaço disponível - cerca de trinta páginas - e não é pautado. A mancha ocupa todo o espaço de cada página.

Não há certeza da data de início dos escritos, que principiam com a análise de uma situação ligada a um contrato de dragagem.

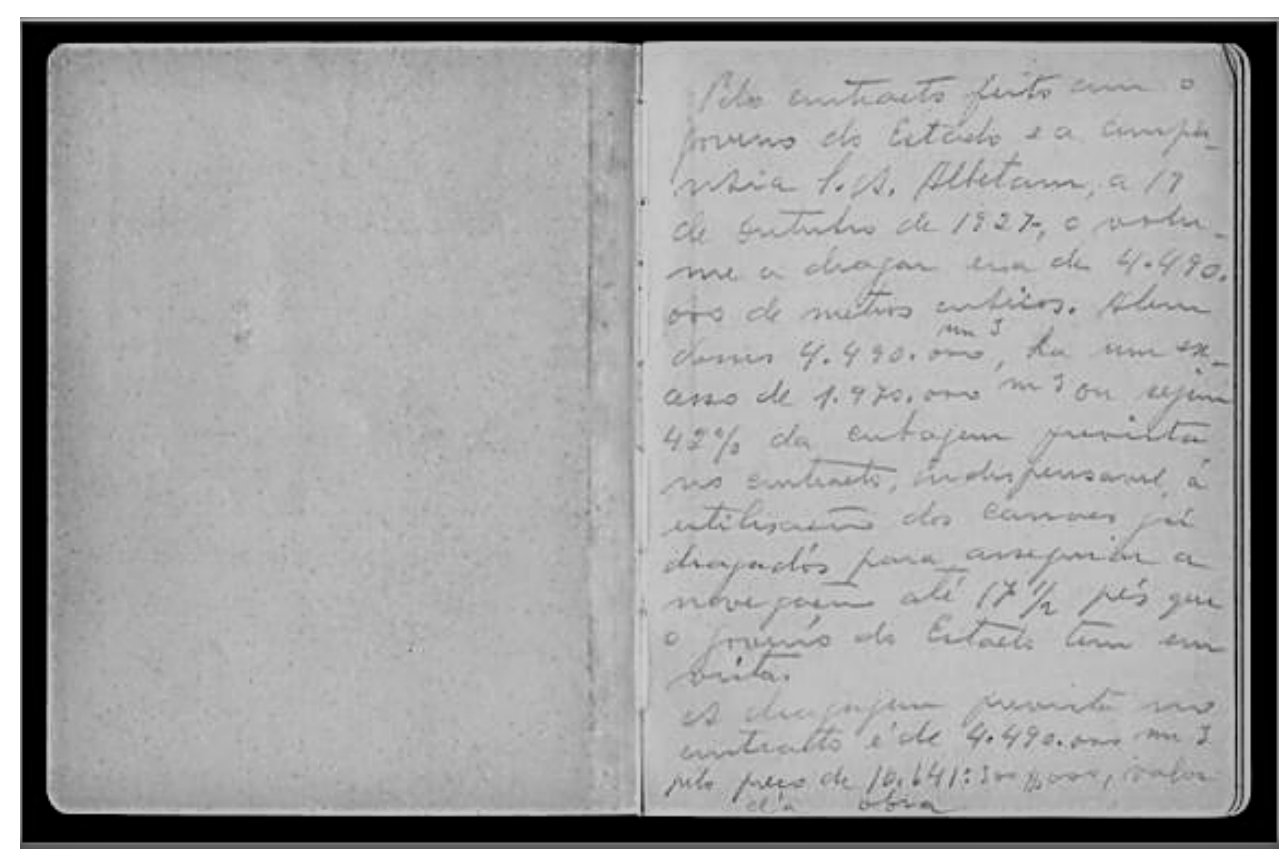

Figura 1. Páginas iniciais do volume 1929 (?) - 10.10.1930

Fonte: https://cpdoc.fgv.br. 
O "diário" propriamente dito se inicia após esse texto, no qual Getúlio explica as razões pelas quais iniciou o trabalho - seria uma forma de aprender com os acontecimentos que se sucederiam:

(01) Se todas as pessoas annotassem diariamente num caderno seus juizos, pensamentos, motivos de acção e as principais ocorrencias em que foi parte, muitos a quem um destino singular impellio, poderiam igualar ás maravilhosas fantasias descritas nos livros de aventuras dos escriptores de mais rica fantasia imaginativa [...]. Lembrei-me que se anotasse diariamente, com lealdade e sinceridade os factos de minha vida, como quem escreve apenas para si mesmo, e não para o publico, teria ali um largo repositorio de factos a examinar e uma lição continua da experiencia a consultar.

E o teor da produção textual contida ali, que parece se repetir nos demais cadernos, é majoritariamente no sentido de registrar fatos de governo, ainda que sob o olhar do escriba e tendo a ele como referência.

Nota-se a presença de mão hábil, que escreve a lápis, com algumas rasuras ao longo do texto. A caligrafia tem certa estabilidade e padrão, mas não parece haver rigor ou cuidado com a escrita. ${ }^{5}$

A escolha do suporte material parece indicar uma certa pressa ou despreocupação - já havia um texto ali escrito, então pode-se argumentar no sentido de que se estaria diante de um caderno próprio para rascunho ou anotações, sem intenção inicial de redigir um diário.

Note-se que, no período especulado para o início do diário, Getúlio candidatou-se à presidência fazendo oposição ao governo de Washington Luís; perdeu a eleição para Júlio Prestes, mas depois assumiu o poder quando este último foi impedido de tomar posse, um pouco depois do final deste volume, em novembro de 1930 - encerrando a República Velha e dando início ao chamado Estado Novo.

A possibilidade de se tornar presidente da República teria despertado em Getúlio o interesse no registro dos fatos ao seu redor? É leviano afirmar com certeza, especialmente porque o ponto de vista bakhtiniano é avesso à subjetividade sem concretude, mas a proximidade dos dois fatos pode não ser mera coincidência.

50 caderno sem pauta, a exemplo do modelo clássico da marca Moleskine (que associa essa ideia a seus produtos, como se pode ver em seu website - http://www.moleskine.com/br/moleskineworld, acesso em 29.8.2018), parece favorecer a liberdade de escrita e o fluxo livre das ideias porém, não há provas de uma escolha deliberada a esse respeito. 
Aliás, o trecho transcrito acima, em especial, quando ele diz que o diário é interessante àqueles "a quem um destino singular impellio", parece reforçar essa possibilidade, que também é sustentada por tudo quanto foi exposto no item 3.2.

O enunciado que parece transparecer do conjunto formado pelo texto e pelo suporte material parece, portanto, trazer um olhar mais voltado para o eu, ainda que trate de temas públicos - tais temas estão relacionados com a atuação pessoal do próprio Getúlio, que se intensifica à medida em que ele vai se aproximando do maior cargo público do País. Vejamos se os outros volumes consultados confirmam essa impressão.

\subsection{Volume 11.11.1930 a 3.2.1931}

Este volume é um pouco mais grosso, com cerca de 200 páginas, mas Getúlio optou por um modelo com pauta quadriculada, o que sugere maior ordenação do texto escrito (que efetivamente existe).

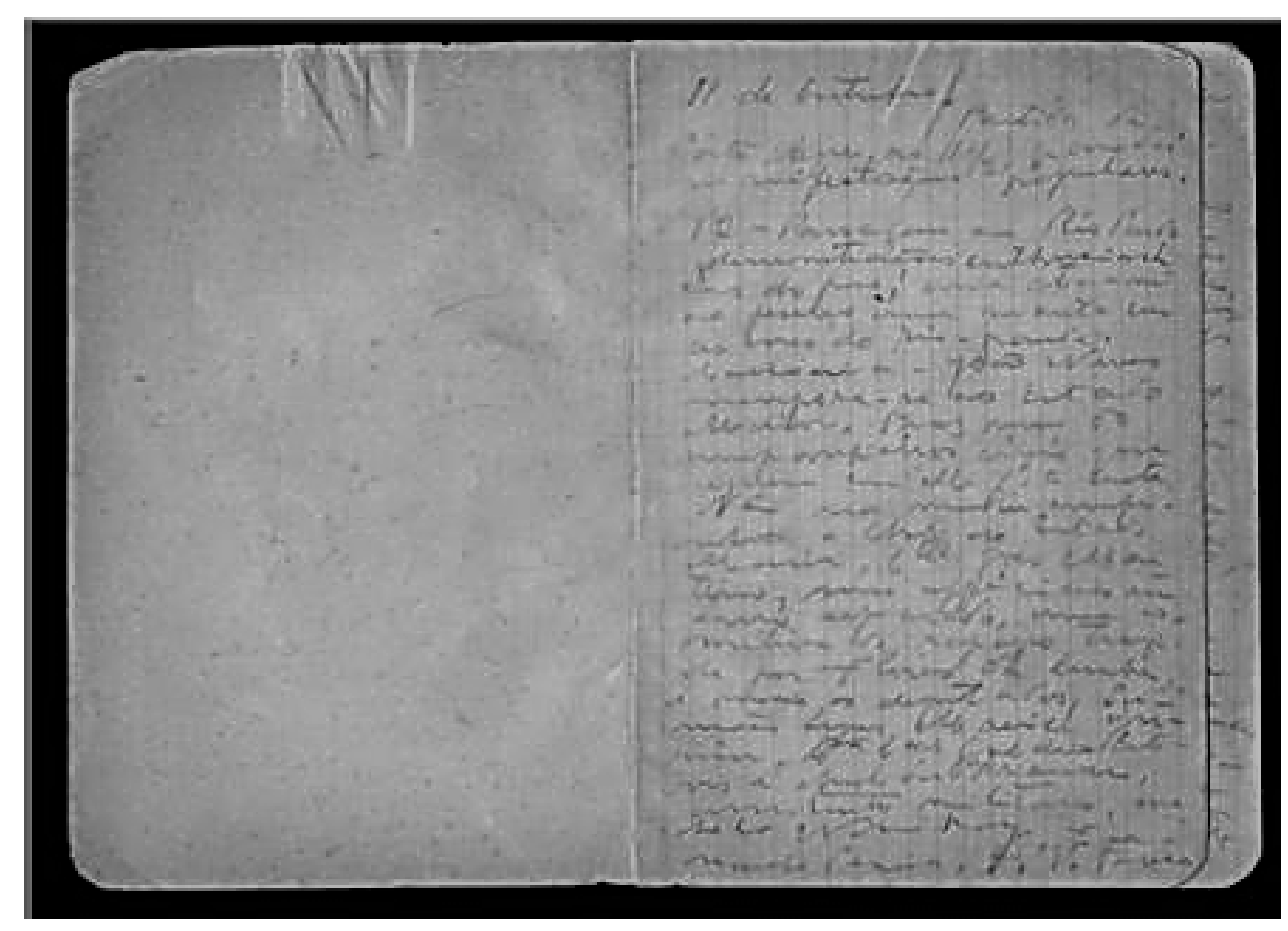

Figura 2. Primeira página do Volume 11.11.1930 a 3.2.1931

Fonte: https://cpdoc.fgv.br.

O texto continua escrito a lápis; a caligrafia mantém o padrão do volume anterior. Embora o texto esteja, de fato, mais ordenado, há inserções e correções fora do espaço que serviria 
para a linha. A mancha é variável; por vezes, a página à esquerda não é preenchida. 0 caderno ainda parece ser simples, apesar de ter sido adotado o padrão pautado.

Getúlio, nesta época, tomara posse como presidente. A ligeira maior ordenação do texto e o uso exclusivo do caderno para os fins do diário parece indicar que o interesse despertado no ano anterior se manteve.

\subsection{Volume janeiro-julho 1933}

Este volume é composto por caderno pautado e de capa que parece ser dura e resistente, com 162 páginas escritas. Como se pode ver na imagem, a página parece ser "emoldurada", o que nos permite a conclusão no sentido da existência da capa.

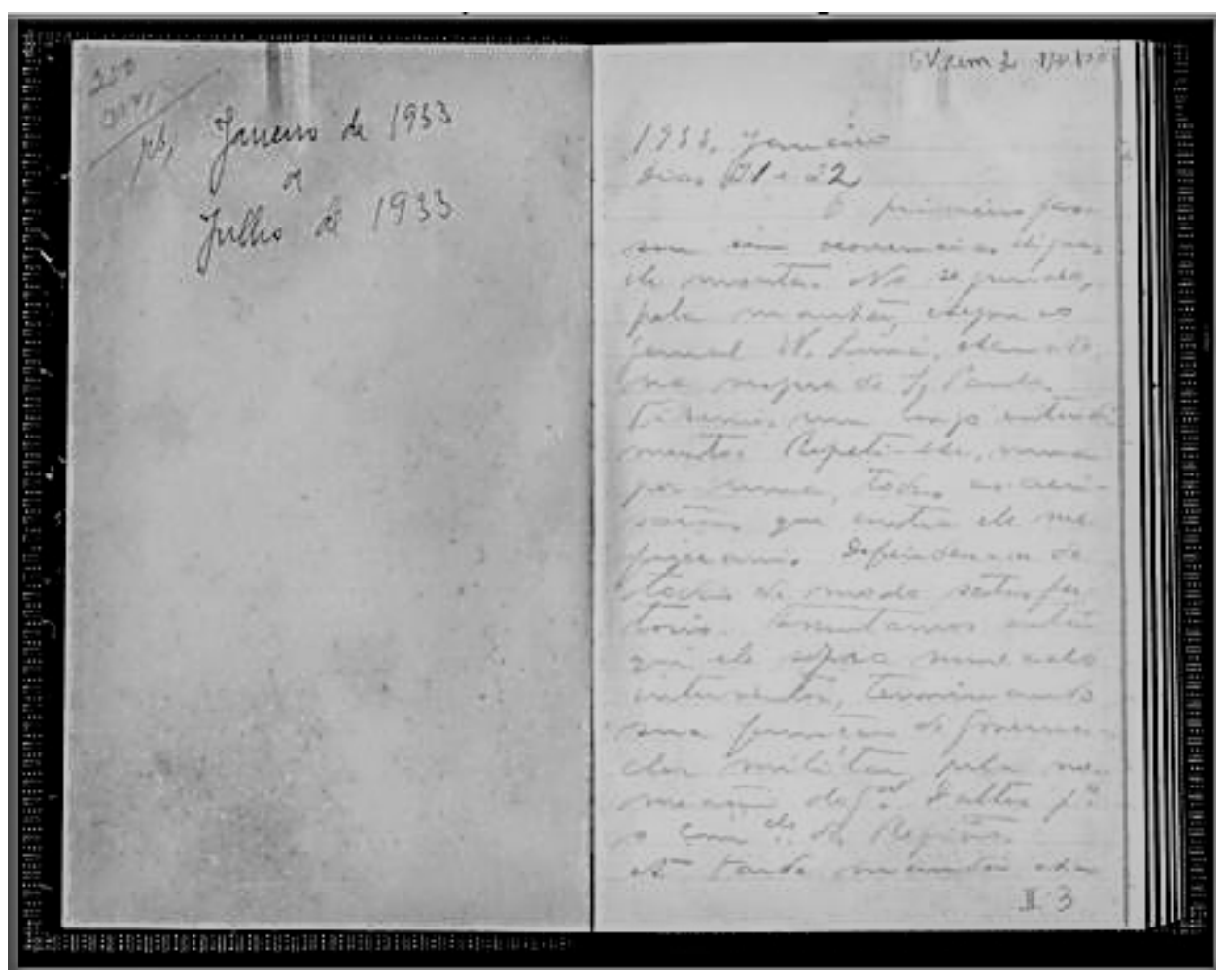

Figura 3. Primeiras páginas do volume janeiro-julho 1933

Fonte: https://cpdoc.fgv.br.

O texto, com melhor distribuição na mancha em função da pauta, vem novamente escrito a lápis, mas a caligrafia é mais regular e cuidada em comparação com os cadernos anteriores. As anotações marginais no cabeçalho e rodapé parecem ter caligrafia distinta da habitualmente atribuída a Getúlio e podem ser de autoria do próprio CPDOC-FGV. 
Há rasuras ao longo do texto que dão a impressão de serem releituras, ${ }^{6}$ bem como a inserção de uma entrada de parágrafo no início do texto de cada dia.

Historicamente, estamos em período pouco posterior à Revolução Constitucionalista de 1932. A democratização estava no ar, sinalizada pelos votos feminino e secreto, bem como pela criação da Justiça Eleitoral, visando o combate à fraude eleitoral. A Assembleia Nacional Constituinte fora eleita (mas só seria instalada mais tarde, depois do final deste volume).

Os sinais codicológicos que exsurgem são no sentido de um maior cuidado com a escolha do suporte e com a disposição do texto; é como se o próprio suporte material destacasse a figura do escriba, que é por si mesma pública e de grande destaque.

\subsection{Volume março 1934-outubro 1935}

Este volume é nitidamente diferente dos anteriores, não apenas na quantidade de páginas (400), mas também em suas dimensões, as quais visualmente aparentam ser maiores do que as dos demais cadernos.

60 CPDOC-FGV informa que alguns trechos dos cadernos possuem inserções de autoria da filha de Vargas, Alzira (cf. http://www.fgv.br/cpdoc/acervo/arquivo-pessoal/GV/textual/diario-pessoalde-getulio-vargas. Acesso em: 30 maio 2019). 


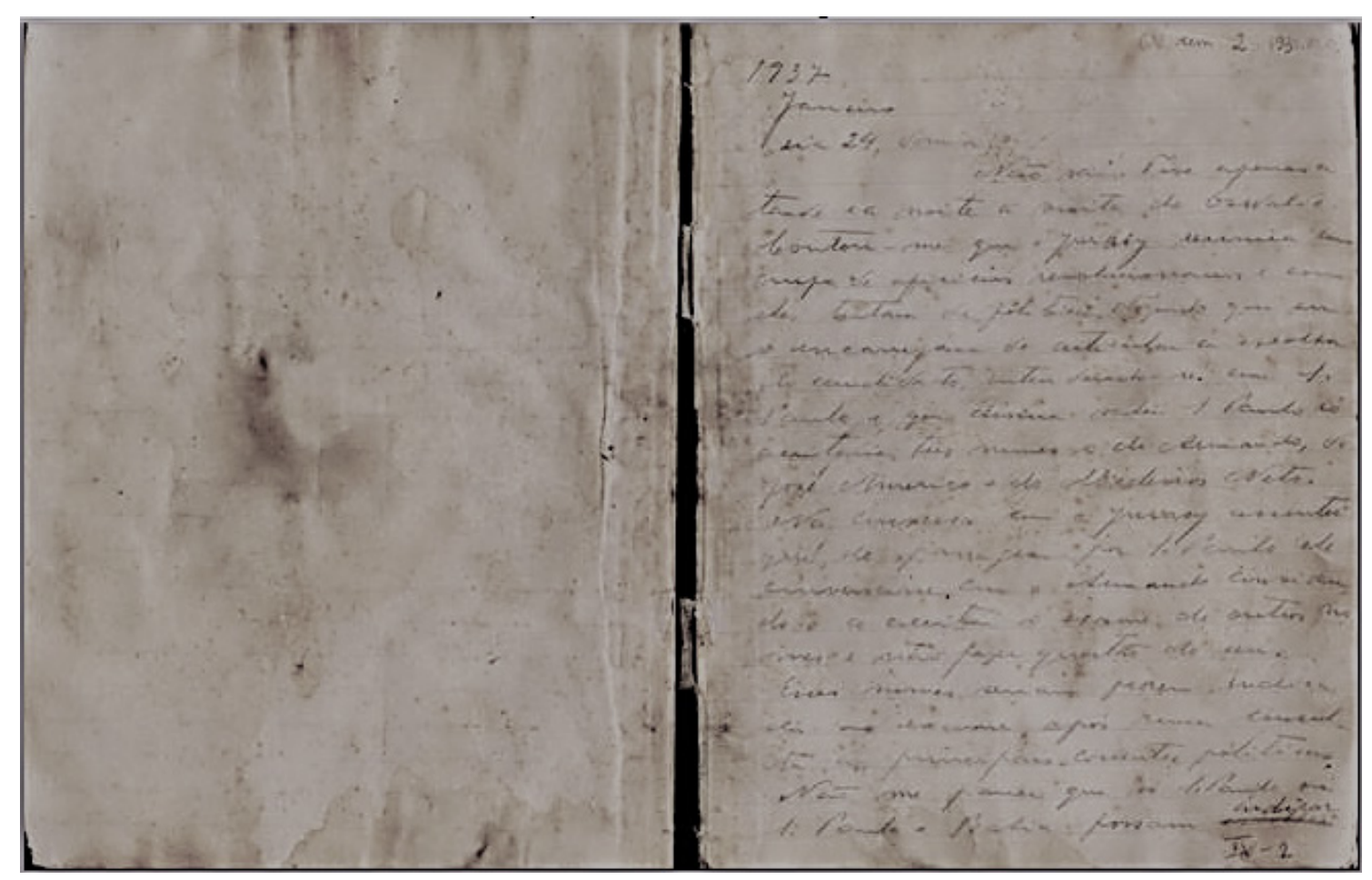

Figura 4. Primeira página do volume março 1934-outubro 1935

Fonte: https://cpdoc.fgv.br.

A caligrafia segue o padrão regular e cuidado do caderno que analisamos anteriormente, e a mancha ocupa todo o espaço disponível. Nota-se que o texto é organizado e dividido em parágrafos, sem, contudo, haver indicação de espaçamento que indique essa divisão, que é inferida a partir do espaço deixado ao final de algumas frases.

Ao invés de inserir entradas por dia, o escriba torna mais frequente o hábito de escrever por blocos de dias. Isso, contudo, não descaracteriza o gênero diário, uma vez que há obediência à ordem cronológica.

O período abrangido por este volume tem como característica marcante o primeiro mandato de Getúlio como presidente eleito, no qual se ampliou a repressão à "ameaça comunista", representada pela ANL, compulsoriamente fechada (fato que, posteriormente, levaria a movimentos que culminariam na Intentona Comunista). Há um aumento visível da legislação "antissubversiva". O terror comunista seria utilizado como desculpa em 1937, por meio do suposto Plano Cohen, para que Getúlio dissolvesse o Congresso e outorgasse uma nova Constituição. 
Codicologicamente, com um caderno volumoso, o sinal que fica é de que Getúlio é "grande". Há sintonia entre esse sinal e os fatos históricos que vão se desenrolando, registrados sob o olhar do presidente.

\subsection{Volume janeiro 1937-janeiro 1939}

Mais um caderno volumoso se apresenta, com suas 400 páginas escritas. 0 período abrangido é maior, em comparação com o material anteriormente analisado, também de 400 páginas; a diferença está em que a maior parte das entradas diárias é mais curta.

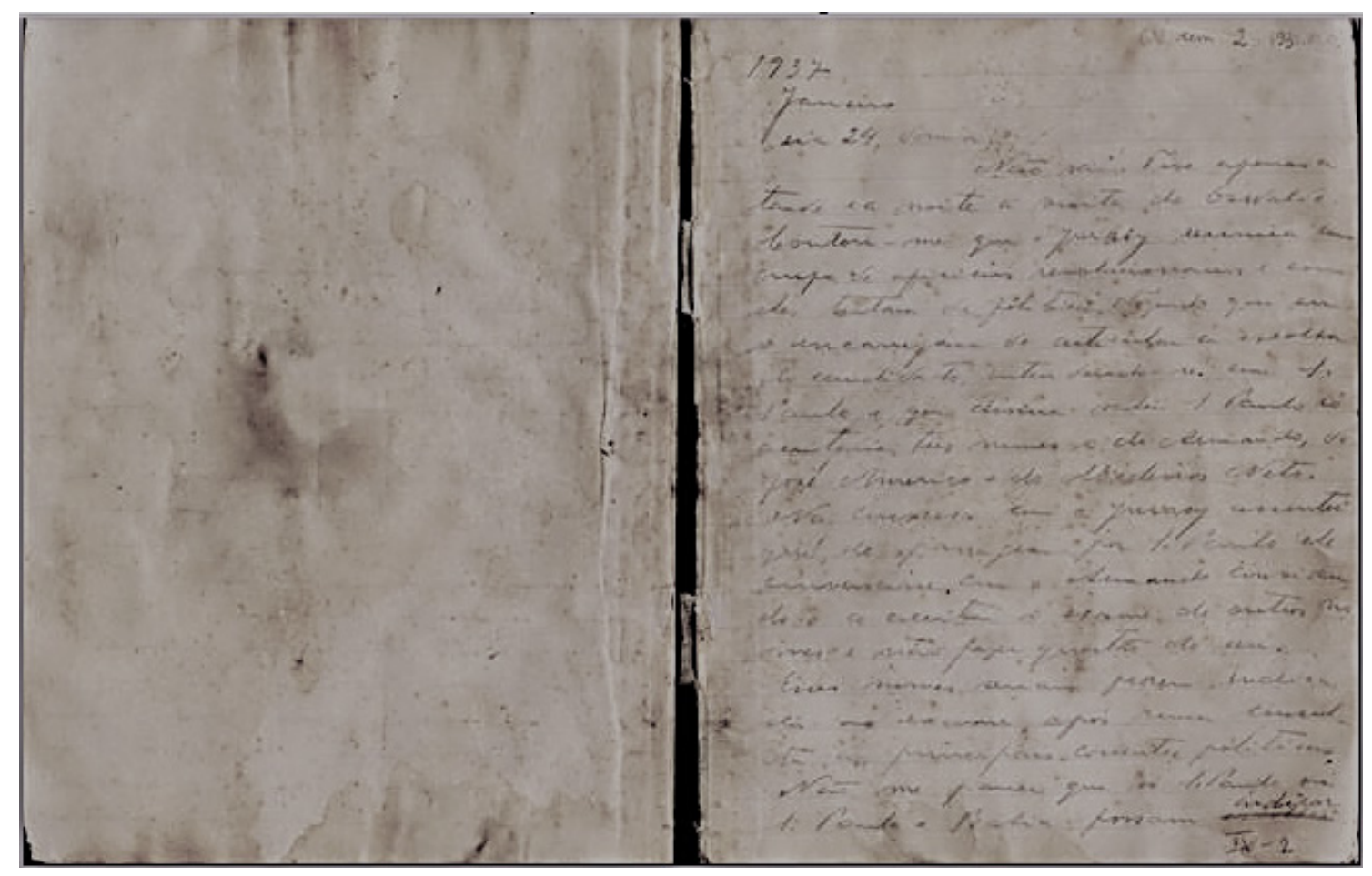

Figura 5. Primeira página do volume janeiro 1937-janeiro 1939

Fonte: https://cpdoc.fgv.br.

Uma característica marcante deste volume em comparação com os acima apresentados está no fato de que ele é escrito a caneta de tinta azul. ${ }^{7}$ A letra é delicada e cuidadosa. Essas características levam à conclusão de que o autor tinha interesse na perenidade de sua memória - já que a tinta é mais resistente ao tempo do que o lápis - e pode ter, inclusive, passado o material a limpo.

7 Embora a imagem esteja em preto e branco, por exigência da publicação, temos a versão a cores da página (também disponível no CPDOC-FGV, on-line), que comprova esse fato. 
O período abrangido por este volume coincide com a instauração do Estado Novo, justificado pela "ameaça comunista", como visto acima. Getúlio determina o fechamento do Congresso Nacional e promulga a Constituição de 1937, que lhe confere pleno controle do Poder Executivo. Os governadores estaduais são substituídos por interventores. Com aparente inspiração no departamento de propaganda do regime nazista (essa sugestão é apresentada no filme de Escorel), é instaurado o DIP (Departamento de Imprensa e Propaganda), que intensifica a censura.

A história e a codicologia parecem andar lado a lado ao nos mostrarem uma centralização imensa da figura de Getúlio, pelos fatos e pelas características físicas do material - tudo isso compõe o enunciado expresso pelo volume.

\subsection{Volume maio 1941-maio 1942}

Este volume dá a impressão de ser ligeiramente menor do que o anteriormente analisado. Tem 162 páginas escritas, mas ao que parece não foi totalmente preenchido, o que pode indicar um desinteresse na continuação do trabalho de registro.

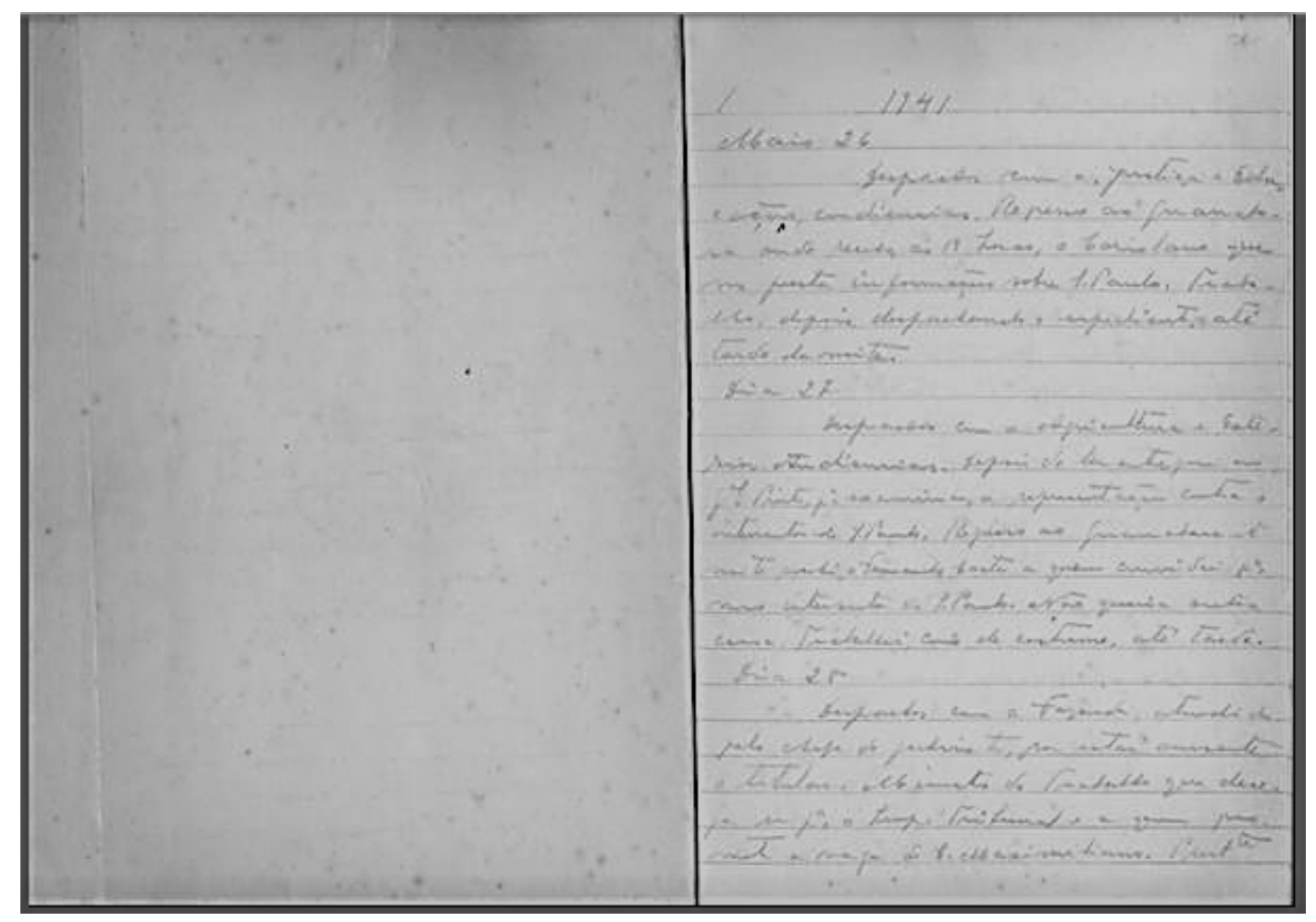

Figura 6. Primeira página do volume maio 1941-maio 1942

Fonte: https://cpdoc.fgv.br. 
O texto também é escrito a caneta, e o cuidado e a organização são visíveis. Porém, o escriba passa grandes períodos sem anotações. E, na última página, depois de meses sem escrever, desiste de manter o diário:

(02) [...] tracei rapidamente estas linhas dando por encerradas as anotações. Para que continual-as após tão longa interrupção $A$ revolta o sofrimento tambem mudou muita coisa em mim!

Este é o período em que finda a ambiguidade do Brasil em suas relações internacionais: Getúlio cortejava Hitler, se inspirou na propaganda nazista, ao mesmo tempo em que era cortejado pelos EUA com promessas de vantagens comerciais em troca de bases aeronáuticas no Nordeste.

Em 1942, o apoio se consolida em favor dos EUA e, depois do final do último volume, - Brasil entra na Segunda Guerra Mundial declarando guerra ao Eixo, após ter navios atacados por submarinos alemães.

Codicologicamente, o material passa a impressão de que tudo é muito limpo, até mesmo asséptico. Tudo transpira correção e, por que não dizer, rigidez. O desinteresse final em continuar os escritos, somado a essa correção excessiva, pode agregar ao enunciado elementos como tédio, obrigação ou cansaço.

Getúlio somente deixaria o poder em 1945, deposto por um golpe militar, que, a julgar pelas imagens recuperadas por Eduardo Escorel, parece ter sido aceito com tranquilidade pelo agora ex-presidente. Ele voltaria ao cargo em 1951.

\section{Outros diários}

Comparando estes trechos com outros "diários" que analisamos, salta aos olhos o costume de passar o texto a limpo, que fica mais evidenciado nos dois volumes escritos a caneta.

Ao que parece, esta era prática relativamente comum para esse gênero discursivo. 0 efeito do ato de "passar a limpo" é um material bem cuidado, legível, compreensível.

Encontramos referência expressa a esse ato em dois "diários" que foram posteriormente publicados: Diário de uma viagem ao Brasil, de Maria Graham (1990), e $O$ turista aprendiz, de Mário de Andrade (2015). Porém, nestes dois casos, fica a dúvida sobre se a intenção de passar a limpo já não estaria diretamente conectada à intenção de publicação. 
Porém, o "diário" que foi objeto da tese de doutorado que fundamenta a argumentação sobre o gênero diário, pertencente a Benedicto de Souza Pinto - o Juca Teles, personagem folclórica de São Luiz do Paraitinga,$-{ }^{8}$ continha trechos escritos a caneta que, em alguns momentos, apresentavam espaços em branco a serem preenchidos, ao que parece, com nomes de pessoas e lugares, que não estavam frescos na memória do escriba. Não há comprovação de que o texto foi passado a limpo, mas a falta quase absoluta de rasuras para um texto escrito a tinta faz supor isso.

De qualquer forma, os dois fatos - a falta de rasuras e os espaços estratégicos em branco - são sinais de um cuidado com o registro que reforça tudo quanto foi dito anteriormente a respeito do que se espera de alguém que se utiliza do gênero discursivo diário: a exposição de si mesmo de forma bastante pessoal. O cuidado com a escrita é uma forma de fazer com que essa exposição se dê de modo favorável do ponto de vista estético e garanta a preservação dos escritos; assim, aquele destinatário indefinido poderá, eventualmente, estabelecer seu contato com eles.

\section{Um projeto de imagem}

No caso de Getúlio, além de tudo quanto vimos a respeito do gênero discursivo diário em si, vale retomar o que foi dito a respeito da imagem do então presidente, que, ao longo da escrita dos "diários", estava em ascensão, o que os aspectos codicológicos ajudam a reforçar.

Mas o conteúdo, até o ponto em que o lemos, não parece ser uma obra de propaganda nos moldes do que o DIP preparava. São dados, fatos nos quais o então presidente estava envolvido. Isso não faz com que se descaracterize o gênero diário (até porque tais fatos são sempre ligados à atuação de Getúlio) e não desmerece a tentativa da construção de uma imagem - muito ao contrário, dá a entender que se está diante de alguém que atua, que está trabalhando em prol da solução de questões de governo.

Em análise datada da época em que a transcrição dos volumes foi publicada, Coelho (1995) chega a argumentar que a elaboração do "diário" foi uma "satisfação para o superego" de Getúlio, como se estivesse prestando contas a si mesmo. Para nós, considerando tudo que está relacionado ao enunciado em questão, agregando a essa análise os dados codicológicos, acreditamos que Getúlio o tivesse feito em vista daquele "destino singular" que menciona no primeiro volume.

80 "diário" não foi dado à publicação em vida do autor e não há indícios de que ele tivesse essa intenção. 
Em outras palavras, ele talvez acreditasse que realmente precisava prestar contas do que fazia, mas isso não o diminuía, como a codicologia e os demais fatos históricos envolvendo sua pessoa dão a entender. Na verdade, tal prestação de contas pode ter sido uma forma de expor o quanto seu papel na condução dos destinos do Brasil the parecia relevante e fazer parte do projeto que tinha para manter viva sua imagem quando "entrasse para a História".

\section{Conclusão}

O olhar que dedicamos ao material ora estudado ainda é superficial, visto que, conforme informado, ainda estamos trabalhando na sua edição e aprofundando nossa percepção em relação a ele. Mas essa breve consideração sobre a evolução dos aspectos codicológicos, em sintonia com aspectos da própria vida do escriba, indica o valor discursivo desses aspectos, que podem trazer grande riqueza de leitura para o intérprete.

Some-se a tudo isso o quanto vimos em nossa exposição a respeito do gênero diário: por mais que o autor não tenha tido a intenção de publicar o texto, ele não deixa de ser uma grande "vitrine" de si mesmo.

A reflexão sobre a posteridade e a memória - "que imagem terão de mim no futuro?" pode ter ocupado a mente de Getúlio, e nós, do futuro, estamos hoje ocupando nosso lugar na relação estabelecida pelo autor ao recebermos e processarmos essa mensagem.

\section{REFERÊNCIAS}

ANDRADE, M. de. O turista aprendiz. Edição anotada e documentada por T. A. Lopez e T. L. Figueiredo. Brasília: IPHAN, 2015.

BAKHTIN, M. M. Estética da criação verbal. Tradução Paulo Bezerra. 4. ed. São Paulo: Martins Fontes, 2003.

BAKHTIN, M. M. Para uma filosofia do ato responsável. Tradução V. Miotello e C. A. Faraco. 3. ed. São Carlos: Pedro \& João, 2017.

BRAIT, B.; MELO, R. de. Enunciado/enunciado concreto/enunciação. In: BRAIT, B. (org.). Bakhtin: conceitos-chave. 4. ed. São Paulo: Contexto, 2008. p. 61-78.

CAMBRAIA, C. N. Introdução à crítica textual. São Paulo: Martins Fontes, 2005. 
CENTRO DE PESQUISA E DOCUMENTAÇÃO DA FUNDAÇÃO GETÚLIO VARGAS (CPDOCFGV). Diário pessoal de Getúlio Vargas. Disponível em: http://bit.ly/2XM82ye. Acesso em: 15 maio 2018.

COELHO, M. "Diário" expõe o Getúlio Vargas inapetente. Folha de S. Paulo, São Paulo, 29 dez. 1995. Ilustrada. Disponível em: http://bit.ly/2NT1cYb. Acesso em: 11 set. 2018.

FERNANDES, N. R. Expressão coletiva e gênero textual nos cadernos de Juca Teles do Sertão das Cotias: por um estatuto do gênero diário. 2017. Tese (Doutorado em Filologia e Língua Portuguesa) - Faculdade de Filosofia, Letras e Ciências Humanas, Universidade de São Paulo, São Paulo, 2017.

FIORIN, J. L. Introdução ao pensamento de Bakhtin. São Paulo: Ática, 2008.

GRAHAM, M. Diário de uma viagem ao Brasil. Tradução A. J. L. Belo Horizonte/São Paulo: Itatiaia/Editora da Universidade de São Paulo, 1990.

GRUPO DE ESTUDOS DE GÊNEROS DO DISCURSO. Palavras e contrapalavras: glossariando conceitos, categorias e noções de Bakhtin. São Carlos: Pedro \& João, 2009.

IMAGENS do Estado Novo 1937-45. Direção: E. Escorel. Brasil: Brasil 1500, 2016. 227 min, digital, p\&b/color.

MACHADO, I. Gêneros discursivos. In: BRAIT, B. (org.). Bakhtin: conceitos-chave. 4. ed. São Paulo: Contexto, 2008. p. 151-166.

MUNHOZ, R. F. Filologia e discurso na correspondência oficial do Morgado de Mateus: edição de documentos administrativos e estudo das marcas de avaliatividade. 2015. 2 v. Tese (Doutorado em Filologia e Língua Portuguesa) - Faculdade de Filosofia, Letras e Ciências Humanas, Universidade de São Paulo, São Paulo, 2015.

VARGAS, G. In: DICIONÁRIO histórico-biográfico brasileiro: pós-1930. 2. ed. Rio de Janeiro: FGV-CPDOC, 2001. Versão on-line, em formato HTML. Disponível em: http://bit.ly/2G5o2Wj. Acesso em: 11 set. 2018. 